\title{
Serum fetuin-A levels and its relationship with biochemical parameters in hemodialysis patients
}

\author{
Behzad Abbasi Jamaati $^{\circledR}$, Raheb Ghorbani $^{\circledR}{ }^{\circledR}$, Mehrdad Zahmatkesh $^{\circledR}$, Mohammad Reza Tamadon $^{1^{*}}{ }^{\circledR}$ \\ ${ }^{1}$ Department of Internal Medicine, Semnan University of Medical Sciences, Semnan, Iran \\ ${ }^{2}$ Social Determinants of Health Research Center, Semnan University of Medical Sciences, Semnan, Iran
}

\section{A R T I C L E I N F O}

Article Type:

Original

\section{Article History:}

Received: 7 February 2021

Accepted: 14 April 2021

ePublished: 18 May 2021

\section{Keywords:}

Hemodialysis

Fetuin A

Chronic kidney disease

End-stage renal disease

\begin{abstract}
A B S T R A C T
Introduction: Cardiovascular events are the most important complications of end-stage renal disease (ESRD). The role of fetuin-A and vascular calcification inhibitors in cardiovascular complications, dysregulated biochemical markers, and mortality is uncertain in patients under hemodialysis.

Objectives: The aim of this study was to investigate the relationship of fetuin-A with cardiovascular complications and biochemical markers in hemodialysis patients.

Patients and Methods: In this cross-sectional study, 65 patients undergoing hemodialysis were enrolled. Blood samples were taken at pre-dialysis to determine serum fetuin-A, calcium, phosphorus, intact parathyroid hormone (iPTH), C-reactive protein (CRP), albumin, triglyceride, total cholesterol, as well as blood hemoglobin, and hematocrit. The data was analyzed considering the statistical significance level of 0.05 .

Results: Out of 65 patients, seven patients died during the study, and 58 patients were finally evaluated. Mean $( \pm S D)$ serum fetuin-A level was $1268.71 \pm 1229.4 \mu \mathrm{g} / \mathrm{mL}$. There was no significant difference in the mean fetuin-A level between genders $(P=0.904)$. There were no significant correlations between the serum level of fetuin-A and age, duration of dialysis, heart diseases, serum levels of calcium, phosphorus, PTH, albumin, CRP, cholesterol and finally blood hemoglobin. However, significant relationships were found between fetuin-A level and serum triglyceride (TG) level $(P=0.019)$ and body mass index (BMI) $(P=0.024)$.

Conclusion: Fetuin-A level was significantly associated with serum TG level and BMI. Regarding the links of obesity and hypertriglyceridemia with cardiovascular diseases (CVDs), controlling serum TG level and body weight can reduce the risk of vascular atherosclerosis in patients undergoing dialysis.
\end{abstract}

Implication for health policy/practice/research/medical education:

End-stage renal disease (ESRD) is often associated with several complications. An important matter in these patients is early diagnosis of complications and prevention of their progression. Given the possible relationship between fetuin-A in hemodialysis patients with inhibitors of vascular calcification, atherosclerosis and biochemical markers and the pathogenesis factors involved in atherosclerosis, by confirming the relationship between biochemical markers and fetuin- $\mathrm{A}$ and the effect on vascular calcification it may be possible to reduce complications in hemodialysis patients.

Please cite this paper as: Abbasi Jamaati B, Ghorbani R, Zahmatkesh M, Tamadon MR. Serum fetuin-A levels and its relationship with biochemical parameters in hemodialysis patients. J Renal Inj Prev. 2022; 11(1): e06. doi: 10.34172/jrip.2022.06.

\section{Introduction}

End-stage renal disease (ESRD) is the final stage of kidney failure presenting with uremic syndrome as accumulation and precipitation of uremic toxicants and hemostatic disorder as severe dysregulation of water and electrolytes (1). Dialysis and kidney transplantation are major and important treatments for patients with ESRD.

Hemodialysis is a procedure encompassing a wide range of renal therapies (2). Dialysis is associated with systemic and local complications including oral lesions and altered content and flow rate of the saliva $(3,4)$. On the other hand, salivary functions such as lytic and buffering properties are important to maintain tooth integrity, oral antimicrobial activity, and taste. Alternations in saliva content can further lead to abnormal food digestion (4).

Patients with ESRD are at risk of cardiovascular diseases 
(CVDs) and complications (5,6). Mortality rates are higher among dialysis patients than that of the general population, and CVDs constitute the most common causes of mortality in patients undergoing dialysis (7). Vascular calcification is an important pathologic process predisposing ESRD patients to atherosclerosis and CVDs $(6,7)$.

Recently, the beneficial role of vascular calcification inhibitors has been reported in patients undergoing hemodialysis (6). Prolonged dialysis, advanced age, as well as elevated PTH, C-reactive protein (CRP), dyslipidemia, hyperhomocysteinemia and hypoalbuminemia have been among risk factors of vascular calcification. Other contributors to vascular calcification in patients with ESRD include hyperphosphatemia, hypercalcemia, as well as elevated serum calcium phosphate (8). The roles of tumor necrosis factor- $\alpha$, transforming growth factor 23, osteocalcin, osteonectin, core-binding factor- $\alpha 1$, alkaline phosphatase, and bone morphogenetic protein 24, a bone metabolic cytokine, have been suggested in the formation of vascular lesions in studies on smooth muscle and endothelial cells (9-12). Recent findings also indicate that inflammation contributes to the calcification process (13). Inflammation is a multifactorial pathogenic process in ESRD (13). CRP is an inflammatory marker that independent of other mediators is increased in acute inflammation and CVD $(14,15)$. Other studies have also shown that calcification is associated with malnutrition, inflammation, atherosclerosis, as well as increased serum fibrinogen, hypoalbuminemia, and elevated CRP level (16-18).

Fetuin-A, also known as a2-Hermans-Schmid glycoprotein, is a blood circulating protein produced by the liver. During fetal life, the level of this protein is higher than that of albumin. Fetuin-A is a calcium-bonded glycoprotein inhibiting vascular calcification. Other inhibitors of calcification include matrix Gla protein, osteoprotegerin, and osteopontin. (19-21). The prognostic role of fetuin-A has been indicated in dialysis patients.

Large vascular lesions predispose to small-peripheral arterial disease and may subsequently lead to sudden death in ESRD patients undergoing dialysis. Therefore, early diagnosis of atherosclerosis and vascular diseases is essential in these patients. Currently, pulse rate measurement, cardio-ankle vascular index, anklebrachial index, toe-brachial index, and aortic calcification measurement deliver rapid and simple methods for diagnosis of vascular calcification $(22,23)$. Patients with ESRD undergoing hemodialysis variably show vascular calcification as some patients represent with severe disease while others with similar uremia intensity may present no evidence of this pathological condition (24).

A possible role has been suggested for vascular calcification inhibitors including fetuin-A in managing atherosclerosis and its risk factors. In this regard, fetuin-A may be a potential factor to predict vascular calcification and subsequently prevent hemodialysis complications in ESRD patients. Patients with ESRD undergoing dialysis are susceptible to cardiovascular complications, which are the most important causes of death in this condition. Accordingly, fetuin-A may help to identify patients at risk of cardiovascular events and reduce the morbidity and mortality rates.

\section{Objectives}

We aimed to investigate the relationship of fetuin-A with biochemical markers, as well as cardiovascular complications in ESRD patients undergoing dialysis.

\section{Patients and Methods \\ Study design}

In this cross-sectional study, 65 patients referred to the dialysis clinic of the Kosar hospital of Semnan were included. During follow up, seven patients died and therefore the data of 58 patients were finally analyzed.

A checklist was used to record patients' height, weight, blood pressure, and biochemical parameters. Blood samples were taken at pre-dialysis phase to determine serum levels of fetuin-A, calcium, phosphorus, intact parathormone (iPTH), CRP, albumin, triglyceride, total cholesterol, as well as blood hemoglobin, and hematocrit.

\section{Data analysis}

Data were analyzed by SPSS 23 software. Pearson and Spearman's correlation coefficients, Shapiro-Wilk test, and student $t$ test were used to analyze the data. The statistical significance level was considered as $P<0.05$.

\section{Results}

In this study, 65 patients undergoing hemodialysis were studied. In the course of the study, seven patients died, and the data of 58 remaining patients were finally analyzed. Table 1 shows the comparison of mean fetuin-A levels based on demographic data and levels of blood biochemical indicators.

Males constituted $39(60 \%)$ patients. Mean $( \pm S D)$ serum fetuin-A level was $1268.71 \pm 1229.4 \mu \mathrm{g} / \mathrm{mL}$. There was no significant difference comparing serum fetuin-A between men and women $(P=0.904)$. The patients' mean and median ages were $63.4 \pm 6$ and 66 years old respectively (the range of 27 to 88 years). There was no significant correlation between age and fetuin-A level $(r=-0.21$, $P=0.113)$.

The mean patients' body mass index (BMI) was $24.8 \pm$ $4.7 \mathrm{~kg} / \mathrm{m}^{2}$. Overall, $34.5 \%$ and $10.3 \%$ of the patients were overweight and obese respectively. There was a positive and significant correlation between fetuin-A level and BMI $(\mathrm{r}=0.297, P=0.024)$.

The mean and median values of dialysis duration were $4.52 \pm 3.51$ and 3 years respectively (the range of 1 to 
Table 1. Comparison of mean fetuin-A levels based on demographic and blood biochemical indicators

\begin{tabular}{|c|c|c|c|c|c|c|c|c|}
\hline \multirow{2}{*}{ Parameters } & & \multirow{2}{*}{ No (\%) } & \multicolumn{4}{|c|}{ Fetuin-A } & \multirow{2}{*}{$\begin{array}{l}\text { Correlation } \\
\text { coefficient }\end{array}$} & \multirow{2}{*}{$P$ value } \\
\hline & & & Mean & SD & Median & Interquartile range & & \\
\hline \multirow{2}{*}{ Gender } & Male & $26(40)$ & 1110.9 & 971.3 & 809.0 & 569 & \multirow{2}{*}{--} & \multirow{2}{*}{0.904} \\
\hline & Female & $39(60)$ & 1347.8 & 1375.8 & 675.0 & 675 & & \\
\hline \multirow{3}{*}{ Age } & $<60$ & $20(34.4)$ & 1601.8 & 1472.8 & 739.5 & 2433 & \multirow{3}{*}{-0.210} & \multirow{3}{*}{0.113} \\
\hline & $60-69$ & $17(29.3)$ & 1129.2 & 1181.8 & 829 & 530 & & \\
\hline & $>70$ & $21(36.2)$ & 1064.3 & 979.2 & 610 & 520 & & \\
\hline \multirow{3}{*}{ BMI } & $<25$ & $32(55.2)$ & 1102.2 & 1075.2 & 663.5 & 574 & \multirow{3}{*}{0.297} & \multirow{3}{*}{0.024} \\
\hline & $25-29.9$ & $20(34.5)$ & 1142.7 & 1110.4 & 762.0 & 561 & & \\
\hline & $>30$ & $6(10.0)$ & 2577.0 & 1756.4 & 2841.5 & 3363 & & \\
\hline \multirow{3}{*}{$\begin{array}{l}\text { Dialysis } \\
\text { duration (y) }\end{array}$} & $<5$ & $36(62.1)$ & 1192.0 & 1282.8 & 636.5 & 660 & \multirow{3}{*}{0.124} & \multirow{3}{*}{0.353} \\
\hline & $5-9$ & $13(22.4)$ & 1135.4 & 995.5 & 829 & 476 & & \\
\hline & $>10$ & $9(15.5)$ & 1768.1 & 1322.2 & 1105 & 2337 & & \\
\hline \multirow{2}{*}{ Calcium } & $<8.5$ & $17(26.2)$ & 1254.2 & 1209.8 & 751 & 313 & \multirow{2}{*}{0.059} & \multirow{2}{*}{0.842} \\
\hline & $8.5-10.2$ & $48(73.8)$ & 1252.6 & 1246.0 & 675 & 727 & & \\
\hline \multirow{2}{*}{ Phosphorus } & $2.5-4.5$ & $18(27.7)$ & 1298.9 & 1319.0 & 729 & 627 & \multirow{2}{*}{-0.004} & \multirow{2}{*}{0.974} \\
\hline & $>4.5$ & $47(72.3)$ & 1235.5 & 1204.6 & 675 & 566 & & \\
\hline \multirow{2}{*}{ PTH } & $\leq 65$ & 11 (16.9) & 1641.2 & 1582.0 & 811 & 3428 & \multirow{2}{*}{0.096} & \multirow{2}{*}{0.446} \\
\hline & $>65$ & $54(83.1)$ & 1174.0 & 1144.0 & 675 & 691 & & \\
\hline \multirow{2}{*}{ Hemoglobin } & Normal & 50 (76.9) & 1293.6 & 1232.2 & 734.5 & 739 & \multirow{2}{*}{-0.095} & \multirow{2}{*}{0.454} \\
\hline & Abnormal & $15(23.1)$ & 1117.9 & 1243.1 & 663 & 312 & & \\
\hline & $>3.5$ & $14(24.1)$ & 1701.2 & 1653.9 & 703.5 & 3549 & & \\
\hline Albumin & $3.5-5.5$ & 44 (75.9) & 1131.1 & 1104.7 & 729 & 648 & -0.227 & 0.086 \\
\hline$T C_{1}$ & $<200$ & $53(81.5)$ & 1142.2 & 1103.8 & 675 & 550 & דבת 0 & 0010 \\
\hline 10 & $\geq 200$ & $12(18.5)$ & 1742.8 & 1637.5 & 806 & 3276 & & 0.010 \\
\hline & $<200$ & $62(95.4)$ & 1223.4 & 1230.1 & 675 & 569 & & ח \\
\hline Cnotesterol & $\geq 200$ & $3(4.6)$ & 1867.3 & 1203.2 & 1541 & -- & 0.131 & 0.299 \\
\hline & Negative & $39(60)$ & 1261.5 & 1239.4 & 675 & 482 & & \\
\hline & +1 & $5(7.7)$ & 1080.6 & 721.1 & 845 & 1200 & & \\
\hline CRP & +2 & $7(10.8)$ & 1652.4 & 1413.4 & 1105 & 2472 & 0.035 & 0.183 \\
\hline & +3 & $14(21.5)$ & 1216.9 & 1320.2 & 665.5 & 638 & & \\
\hline
\end{tabular}

PTH, parathyroid hormone; TG, triglyceride; BMI, body mass index; CRP, C-reactive protein.

16 years). No significant correlation was found between the duration of dialysis and fetuin-A level $(r=0.124$, $P=0.353)$.

Mean and median values of serum calcium level were $8.7 \pm 0.8$ and $8.8 \mathrm{mg} / \mathrm{dL}$ respectively (the range of 8.5 $10.2 \mathrm{mg} / \mathrm{dL}$ ). Hypocalcemia (i.e. serum calcium <8.5) was observed in $26.2 \%$ of the patients while $73.8 \%$ had normal calcium level (8.5-10.2 $\mathrm{mg} / \mathrm{dL})$. No patient showed serum calcium level higher than normal. There was no significant correlation between serum calcium level and Fetuin-A level ( $r=0.059, P=0.642)$. However, there was a significant correlation between serum calcium level and heart diseases $(P=0.049)$.

The mean and median serum phosphorus level in the patients were $5 \pm 0.8$ and $5 \mathrm{mg} / \mathrm{dL}$ respectively (the range of 3.4-7.5). The serum phosphorus level varied from 2.5 to $4.5 \mathrm{mg} / \mathrm{dL}$ in $27.7 \%$ of the patients while the rest of them had levels $>4.5 \mathrm{mg} / \mathrm{dL}$. There was no significant correlation between serum phosphorus and fetuin-A level $(\mathrm{r}=-0.004, P=0.974)$.

The mean and median values of serum intact PTH were $236.2 \pm 194.7$ and $148 \mathrm{pg} / \mathrm{mL}$ respectively (range; 0.1-571 $\mathrm{pg} / \mathrm{mL}$ ). While $83.1 \%$ of the patients had iPTH level less than $65 \mathrm{pg} / \mathrm{mL}, 15.4 \%$ had normal serum PTH (65-100 $\mathrm{pg} / \mathrm{mL}$ ), and only one patient revealed iPTH level below $10 \mathrm{pg} / \mathrm{mL}$. There was no significant correlation between serum PTH level and fetuin-A $(\mathrm{r}=0.096, P=0.446)$.

The mean hemoglobin $10.9 \pm 1.4 \mathrm{~g} / \mathrm{dL}$ (range; 7.1-13.9 $\mathrm{g} / \mathrm{dL}$ ) with a median value of $10.9 \mathrm{~g} / \mathrm{dL}$. Normal range hemoglobin (11-12) was observed in $23.1 \%$ while $52.3 \%$ and $24.6 \%$ of the patients had hemoglobin values of $<11$ and $>12 \mathrm{~g} / \mathrm{dL}$ respectively. There was no significant correlation between hemoglobin and fetuin-A $(r=-0.095$, $P=0.454)$.

The mean serum albumin level was $3.78 \pm 0.43 \mathrm{~g} / \mathrm{dL}$ (the range of $3-5 \mathrm{~g} / \mathrm{dL}$ ). The median value of albumin was also 3.75 with $75.9 \%$ of the patients had normal albumin (3.5-5.5 g/dL), and the rest showed values of $<3.5$. There 
was no significant correlation between serum albumin and fetuin-A ( $\mathrm{r}=-0.227, P=0.086)$.

The mean serum TG level was $127.6 \pm 82.9 \mathrm{mg} / \mathrm{dL}$ (30510 ) with the median value of 101 . Overall, $81.5 \%$ of the patients had normal (i.e. <200) and the rest had TG level $>200$. There was a significant correlation between serum TG and fetuin-A ( $\mathrm{r}=281, P=0.023)$.

The mean and median values of serum cholesterol were $136.7 \pm 38.7 \mathrm{mg} / \mathrm{dL}$ (the range of $74-272 \mathrm{mg} / \mathrm{dL}$ ) and 133 respectively. Most of the patients (95.4\%) had normal cholesterol $(<200)$, and the rest had levels greater than $200 \mathrm{mg} / \mathrm{dL}$. No significant correlation was found between serum cholesterol level and fetuin-A $(r=0.131, P=0.299)$.

Serum CRP was negative in $60 \%$ of the patients. No significant correlation was detected between fetuin-A and serum CRP ( $\mathrm{r}=0.035, P=0.783$ ).

The mean value of serum albumin was $3.78 \pm 0.43 \mathrm{~g} / \mathrm{dL}$ (the range of 3-5 g/dL). The median serum albumin was also $3.75 \mathrm{~g} / \mathrm{dL}$. Most of the patients (75.9\%) represented normal serum albumin (3.5-5.5 g/dL) and the rest showed hypoalbuminemia. A significant inverse correlation was found between serum albumin level and the risk of heart diseases $(P=0.012)$.

The mean and median values of fetuin-A were calculated as $1421.60 \pm 1438.66 \mu \mathrm{g} / \mathrm{mL}$ and $663.50 \mu \mathrm{g} / \mathrm{mL}$ in patients with heart diseases and $1188.24 \pm 1116.48 \mu \mathrm{g} / \mathrm{mL}$ in those with no heart diseases $(P=0.532)$.

\section{Discussion}

In this study, from 65 patients undergoing hemodialysis, seven patients died during the study, and therefore the data of 58 patients were analyzed. The mean level of fetuin-A was not significantly different between males and females $(P=0.904)$. In addition, there were no significant correlations between fetuin-A level and age, duration of dialysis, heart diseases, serum levels of calcium, phosphorus, PTH, albumin, CRP and cholesterol, or blood hemoglobin. On the other hand, significant relationships were found between fetuin-A level and serum TG $(P=0.019)$ and BMI $(P=0.024)$. In subgroup analyses based on gender, age, duration of dialysis, number of dialysis sessions and BMI, no significant relationships were detected between fetuin-A and other biochemical markers $(P<0.05)$.

In our study, there was no significant difference in the level of fetuin-A between males and females which was contradictory to the result of $\mathrm{Xu}$ et al in 2011. This may be because $\mathrm{Xu}$ et al measured the level of fetuin-A in patients with metabolic syndrome which differed from the population evaluated in the present study (25).

We also found no significant relationship between age and fetuin-A $(P=0.113, \mathrm{r}=-0.210)$ which was in line with the study of Stenvinkel et al on 258 dialysis patients in Sweden in 2005 (26). However, this finding again opposed the findings of $\mathrm{Xu}$ et al who reported a significant relationship between age and fetuin-A level in patients with metabolic syndrome (25). This discrepancy can also be explained by different populations studied in these reports.

There was a significant positive correlation between BMI and fetuin-A level among dialysis patients in the current study ( $\mathrm{r}=0.297, P=0.024)$. This observation was supported by the report of $\mathrm{Xu}$ et al (25). In another study by Brix et al on 65 obese $(\mathrm{BMI}=45)$ and 21 over-weight $(\mathrm{BMI}=26)$ women undergoing gastric bypass surgery, the level of fetuin-A was significantly higher in the case than the control group at 16 months post-surgery (27).

In our study, no statistically significant associations were detected between fetuin-A level and neither serum iPTH $(\mathrm{r}=0.096, P=0.446)$ nor blood hemoglobin $(\mathrm{r}=-0.095$, $P=0.454)$ which correlated with the report of Oikawa et al on 40 hemodialysis patients (28).

In this study, no significant association was observed between fetuin-A level and serum albumin $(r=-0.227$, $P=0.086$ ) which was consistent with the report of Stenvinkel et al in 2005 (26). Furthermore, we found a significant inverse correlation between serum albumin level and the risk of heart diseases $(P=0.012)$, and this association was exaggerated in albumin level $<3.5 \mathrm{~g} / \mathrm{dL}$. Accordingly, it seems that hypoalbuminemia augments cholesterol precipitation and vascular calcification independent of serum cholesterol level.

There was no significant relationship between fetuin-A and serum CRP level $(\mathrm{r}=0.035, P=0.783)$. This finding contradicted the reports of Oikawa et al (28). The reason for this discrepancy may be related to the methods of CRP measurement (i.e. qualitative in the recent reports and qualitative in our study). Nevertheless, our result was consistent with the study of Stenvinkel et al who described no significant association between serum CRP and fetuin-A (26).

We showed a significant positive correlation between serum TG and fetuin-A levels $(r=0.281, P<0.023)$. This finding was in line with the study of Oikawa et al (28), but it is contradicted with the report of $\mathrm{Xu}$ et al on patients with metabolic syndrome (25). Furthermore, we found no association between the levels of fetuin-A and cholesterol.

Moreover, no significant relationship between fetuin-A and serum calcium level was detected $(\mathrm{r}=0.059, P=0.842)$. However, Pertosa et al noted a significant and inverse correlation between serum calcium and fetuin-A levels (36). This contradiction may be explained by the relatively low power of our study. Nevertheless, we identify a significant relationship between serum calcium level and the risk of CVDs which was consistent with the study of Pertosa et al (29).

We here investigated the association of fetuin-A with serum phosphorus $(\mathrm{r}=-0.004, P=0.0974)$ and dialysis duration ( $r=0.124, P=0.353$,). Nevertheless, neither of these indicators significantly correlated with fetuin-A level. 


\section{Conclusion}

Our results showed that fetuin-A level significantly correlated with BMI and serum TG level. Although there was no significant difference in the level of fetuin-A between dialysis patients with or without CVDs, subgroup analysis revealed a significant inverse correlation between $\mathrm{BMI}$ and fetuin-A indicating a potential protective effect for fetuin-A against CVDs independent of obesity. The statistical power of our study was relatively low because of small sample size partly due to the death of seven patients during data collection. Studies with larger sample sizes can provide more precise and valid information.

\section{Recommendations}

It is suggested to evaluate more biochemical parameters in a comprehensive study with larger sample size to obtain more valid conclusions on the importance of fetuin-A in dialysis patients.

\section{Limitations of the study}

The main limitation of this study was the lack of a control group. The presence of the control group leads to better conclusions and comparison of the relationship between fetuin-A and other biochemical parameters in patients and healthy individuals.

\section{Authors' contribution}

MRT, BAJ and MZ were the principal investigators of the study. MRT and RG were included in preparing the concept and design. MRT and MZ revisited the manuscript and critically evaluated the intellectual contents. All authors participated in preparing the final draft of the manuscript, revised the manuscript and critically evaluated the intellectual contents. All authors have read and approved the content of the manuscript and confirmed the accuracy or integrity of any part of the work.

\section{Conflicts of interest}

The authors declare that they have no competing interests.

\section{Ethical issues}

The research followed the tenets of the Declaration of Helsinki. The Ethics Committee of Semnan University of Medical Sciences approved this study (IR.SEMUMS. REC.1396.127). Accordingly, written informed consent was taken from all participants before any intervention. This study was extracted from M.D thesis Behzad Abbasi Jamaati at this university (Thesis \#1294). Moreover, ethical issues (including plagiarism, data fabrication, double publication) have been completely observed by the authors.

\section{Funding/Support}

This study was supported by research deputy of Semnan University of Medical Sciences (Grant\# 1294).

\section{References}

1. Benjamin O, Lappin SL. End-Stage Renal Disease. [Updated 2020 Nov 19]. In: StatPearls [Internet]. Treasure Island (FL): StatPearls Publishing; 2020 .

2. Tomás I, Marinho JS, Limeres J, Santos MJ, Araújo L, Diz P. Changes in salivary composition in patients with renal failure. Arch Oral Biol. 2008;53:528-32. doi: 10.1016/j.archoralbio.2008.01.006.

3. Kerr AR. Update on renal disease for the dental practitioner. Oral Surg Oral Med Oral Pathol Oral Radiol Endod. 2001;92:9-16. doi: 10.1067/ moe.2001.115976.

4. Humphrey SP, Williamson RT. A review of saliva: normal composition, flow, and function. J Prosthet Dent. 2001;85:162-9. doi: 10.1067/mpr.2001.113778.

5. Lindner A, Charra B, Sherrard DJ, Scribner BH. Accelerated atherosclerosis in prolonged maintenance hemodialysis. N Engl J Med. 1974;290:697-701. doi: 10.1056/NEJM197403282901301.

6. Foley RN, Parfrey PS, Sarnak MJ. Clinical epidemiology of cardiovascular disease in chronic renal disease. Am J Kidney Dis. 1998;32:S112-9. doi: 10.1053/ajkd.1998.v32.pm9820470.

7. Tsuruya K, Hirakata H. Japanese Society for Dialysis Therapy guidelines for management of cardiovascular diseases in patients on chronic hemodialysis. Ther Apher Dial. 2012;16:384-6. doi: 10.1111/j.17449987.2012.01117.x.

8. Wang AY, Lam CW, Chan IH, Wang M, Lui SF, Sanderson JE. Long-term mortality and cardiovascular risk stratification of peritoneal dialysis patients using a combination of inflammation and calcification markers. Nephrol Dial Transplant. 2009;24:3826-33. doi: $10.1093 /$ ndt/gfp325.

9. Shioi A, Katagi M, Okuno Y, Mori K, Jono S, Koyama $\mathrm{H}$, Nishizawa Y. Induction of bone-type alkaline phosphatase in human vascular smooth muscle cells: roles of tumor necrosis factor-alpha and oncostatin $\mathrm{M}$ derived from macrophages. Circ Res. 2002;91:916. doi: 10.1161/01.res.0000026421.61398.f2.

10. Moe SM, Duan D, Doehle BP, O’Neill KD, Chen NX. Uremia induces the osteoblast differentiation factor Cbfa1 in human blood vessels. Kidney Int. 2003;63:1003-11. doi: 10.1046/j.15231755.2003.00820.x.

11. ADHR Consortium. Autosomal dominant hypophosphataemic rickets is associated with mutations in FGF23. Nat Genet. 2000;26:345-8. doi: $10.1038 / 81664$.

12. Imanishi $Y$, Inaba $M$, Nakatsuka $K$, Nagasue $K$, Okuno S, Yoshihara A, Miura M, Miyauchi A, Kobayashi K, Miki T, Shoji T, Ishimura E, Nishizawa Y. FGF-23 in patients with end-stage renal disease on hemodialysis. Kidney Int. 2004;65:1943-6. doi: 10.1111/j.15231755.2004.00604.x. 
13. Tintut $Y$, Patel J, Territo M, Saini T, Parhami F, Demer LL. Monocyte/macrophage regulation of vascular calcification in vitro. Circulation. 2002 Feb 5;105:6505. doi: 10.1161/hc0502.102969.

14. Rost NS, WolfPA, Kase CS, Kelly-Hayes M, Silbershatz H, Massaro JM, D’Agostino RB, Franzblau C, Wilson PW. Plasma concentration of C-reactive protein and risk of ischemic stroke and transient ischemic attack: the Framingham study. Stroke. 2001;32:2575-9. doi: 10.1161/hs1101.098151.

15. Albert CM, Ma J, Rifai N, Stampfer MJ, Ridker PM. Prospective study of C-reactive protein, homocysteine, and plasma lipid levels as predictors of sudden cardiac death. Circulation. 2002;105:2595-9. doi: 10.1161/01.cir.0000017493.03108.1c.

16. Goodman WG, Goldin J, Kuizon BD, Yoon C, Gales $\mathrm{B}$, Sider D, et al. Coronary-artery calcification in young adults with end-stage renal disease who are undergoing dialysis. N Engl J Med. 2000;342:1478-83. doi: 10.1056/NEJM200005183422003.

17. Guérin AP, London GM, Marchais SJ, Metivier F. Arterial stiffening and vascular calcifications in end-stage renal disease. Nephrol Dial Transplant. 2000;15:1014-21. doi: 10.1093/ndt/15.7.1014.

18. Stompór T, Pasowicz M, Sulłowicz W, DembińskaKieć A, Janda K, Wójcik K, et al. An association between coronary artery calcification score, lipid profile, and selected markers of chronic inflammation in ESRD patients treated with peritoneal dialysis. Am J Kidney Dis. 2003;41:203-11. doi: 10.1053/ ajkd.2003.50005.

19. Ketteler M, Bongartz P, Westenfeld R, Wildberger JE, Mahnken AH, Böhm R, et al. Association of low fetuin-A (AHSG) concentrations in serum with cardiovascular mortality in patients on dialysis: a cross-sectional study. Lancet. 2003;361:827-33. doi: 10.1016/S0140-6736(03)12710-9.

20. Wang AY, Woo J, Lam CW, Wang M, Chan IH, Gao P, et al. Associations of serum fetuin-A with malnutrition, inflammation, atherosclerosis and valvular calcification syndrome and outcome in peritoneal dialysis patients. Nephrol Dial Transplant. 2005;20:1676-85. doi: 10.1093/ndt/gfh891.

21. Stenvinkel P, Heimbürger O, Paultre F, Diczfalusy U, Wang T, Berglund L, et al. Strong association between malnutrition, inflammation, and atherosclerosis in chronic renal failure. Kidney Int. 1999;55:1899-911. doi: 10.1046/j.1523-1755.1999.00422.x.

22. Munakata M, Sakuraba J, Tayama J, Furuta T, Yusa A, Nunokawa T, et al. Higher brachial-ankle pulse wave velocity is associated with more advanced carotid atherosclerosis in end-stage renal disease. Hypertens Res. 2005;28:9-14. doi: 10.1291/hypres.28.9.

23. Nitta K, Akiba T, Suzuki K, Uchida K, Ogawa T, Majima $\mathrm{K}$, et al.Assessment of coronary artery calcification in hemodialysis patients using multidetector spiral CT scan. Hypertens Res. 2004;27:52733. doi: 10.1291/hypres.27.527.

24. Moe SM, Reslerova M, Ketteler M, O'neill K, Duan D, Koczman J, et al. Role of calcification inhibitors in the pathogenesis of vascular calcification in chronic kidney disease (CKD). Kidney Int. 2005;67:2295-304. doi: 10.1111/j.1523-1755.2005.00333.x.

25. Xu Y, Xu M, Bi Y, Song A, Huang Y, Liu Y, et al. Serum fetuin-A is correlated with metabolic syndrome in middle-aged and elderly Chinese. Atherosclerosis. 2011;216:180-6. doi: 10.1016/j. atherosclerosis.2011.01.020.

26. Stenvinkel P, Wang K, Qureshi AR, Axelsson J, PecoitsFilho R, Gao P, et al. Low fetuin-A levels are associated with cardiovascular death: Impact of variations in the gene encoding fetuin. Kidney Int. 2005;67:2383-92. doi: 10.1111/j.1523-1755.2005.00345.x.

27. Brix JM, Stingl H, Höllerl F, Schernthaner GH, Kopp HP, Schernthaner G. Elevated Fetuin-A concentrations in morbid obesity decrease after dramatic weight loss. J Clin Endocrinol Metab. 2010;95:4877-81. doi: 10.1210/jc.2010-0148.

28. Oikawa O, Higuchi T, Yamazaki T, Yamamoto C, Fukuda N, Matsumoto K. Evaluation of serum fetuin-A relationships with biochemical parameters in patients on hemodialysis. Clin Exp Nephrol. 2007;11:304-308. doi: 10.1007/s10157-007-0499-y.

29. Pertosa G, Simone S, Ciccone M, Porreca S, Zaza G, Dalfino G, et al. Serum fetuin a in hemodialysis: a link between derangement of calcium-phosphorus homeostasis and progression of atherosclerosis? Am J Kidney Dis. 2009;53:467-74. doi: 10.1053/j. ajkd.2008.10.046.

Copyright (c) 2022 The Author(s); Published by Nickan Research Institute. This is an open-access article distributed under the terms of the Creative Commons Attribution License (http://creativecommons.org/licenses/by/4.0), which permits unrestricted use, distribution, and reproduction in any medium, provided the original work is properly cited. 